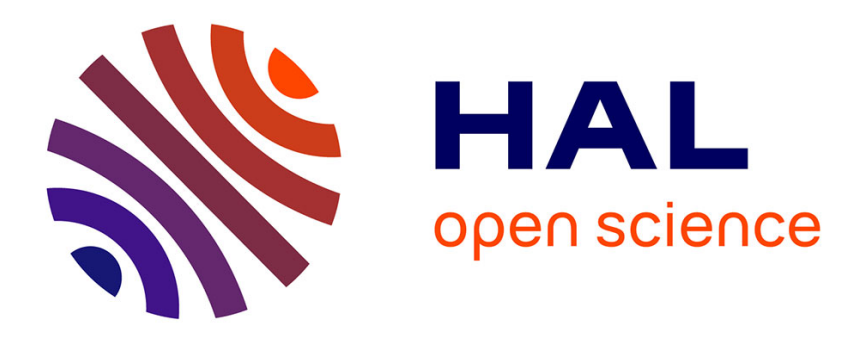

\title{
Structural instabilities in rare earth intermetallic compounds with CsCl structure
}

\author{
B. Lüthi, R. Sommer, P Morin
}

\section{To cite this version:}

B. Lüthi, R. Sommer, P Morin. Structural instabilities in rare earth intermetallic compounds with $\mathrm{CsCl}$ structure. Journal de Physique Colloques, 1979, 40 (C5), pp.C5-139-C5-140. 10.1051/jphyscol:1979551 . jpa-00218968

\section{HAL Id: jpa-00218968 https://hal.science/jpa-00218968}

Submitted on 1 Jan 1979

HAL is a multi-disciplinary open access archive for the deposit and dissemination of scientific research documents, whether they are published or not. The documents may come from teaching and research institutions in France or abroad, or from public or private research centers.
L'archive ouverte pluridisciplinaire HAL, est destinée au dépôt et à la diffusion de documents scientifiques de niveau recherche, publiés ou non, émanant des établissements d'enseignement et de recherche français ou étrangers, des laboratoires publics ou privés. 


\title{
Structural instabilities in rare earth intermetallic compounds with $\mathrm{CsCl}$ structure
}

\author{
B. Lüthi and R. Sommer \\ Physikalisches Institut der Universität, D-6000 Frankfurt a.M., F.R.G. \\ and P. Morin \\ Laboratoire L.-Néel, C.N.R.S., Grenoble Cedex, France
}

\begin{abstract}
Résumé. - Un grand nombre de composés de terres rares métalliques et de structure de type CsCl présentent des transitions de structure cristallographique. Les mécanismes responsables de ces transitions sont un couplage du réseau avec des bandes $5 \mathrm{~d}$ (effet Jahn Teller de bande) ou avec les moments quadrupolaires $4 \mathrm{f}$ (effet Jahn Teller). Les mesures récentes de la vitesse de propagation du son ont permis d'étudier l'amollissement du mode normal de déformation tétragonale dans l'état paramagnétique de $\mathrm{Tm} \mathrm{Zn}$ et $\mathrm{TmCd}$. Les coefficients magnétoélastiques et d'échange quadrupolaire sont déduits. Le comportement sous champ magnétique est aussi discuté.
\end{abstract}

\begin{abstract}
Many intermetallic rare earth compounds with $\mathrm{CsCl}$ structure undergo structural phase transitions. The responsible mechanisms for these transitions are a deformation potential coupling for $5 \mathrm{~d}$ bands (band Jahn Teller effect) or a strain coupling to $4 \mathrm{f}$ quadrupoles (Jahn Teller effect). Recent measurements of the soft elastic modes in the paramagnetic region for $\mathrm{TmZn}$ and $\mathrm{TmCd}$ enable us to determine magnetoelastic and quadrupolar coupling constants. Magnetic field effects on elastic constants are also discussed.
\end{abstract}

In intermetallic rare earth compounds one can have two kinds of structural instabilities, one due to an electronic ordering of $4 \mathrm{f}$ shell electrons (cooperative Jahn Teller effect) and a martensitic type of transformation due to a strain deformation potential coupling to the $5 \mathrm{~d}$ electrons (band Jahn Teller effect). The latter effect has been investigated in some detail in the CsCl-structure $\operatorname{LaAg}_{x} \mathrm{In}_{1-x}$ [1] system and somewhat less in $\mathrm{LaCd}$ [1], CeAg [2]. For the cooperative Jahn Teller effect one has to distinguish between cases where the structural transition temperature $T_{\mathrm{a}}$ and the magnetic transition temperature $T_{\mathrm{C}}, T_{\mathrm{N}}$ are equal or different. Up to the present only two cases have been identified in which $T_{\mathrm{a}}>T_{\mathrm{C}}: \operatorname{TmCd}[3]$ and $T m Z n$ [4]. In other cases [5] ErZn, DyZn $T_{\mathrm{C}}=T_{\mathrm{a}}$ as well as also for the pnictides [6] (DySb, HoSb, $\mathrm{TbP}$, etc.). It is no lucky coincidence that $\mathrm{TmCd}$, TmZn show a pure cooperative Jahn Teller effect. The $\mathrm{Tm}^{3+}$ ion with $J=6$ has $L=5, S=1$ which favors quadrupolar coupling over exchange effects. Indeed all the Tm-pnictides are nonmagnetic and
TmCd, TmZn show structural transitions at temperatures higher than $T_{\mathrm{c}}$ (see table I). We would like to give a brief account of a recent ultrasonic study of these latter two materials.

In figure 1 we present the temperatures dependence of some elastic stiffness constants for $\mathrm{TmZn}$. One notices the strong softening of the $c_{11}-c_{12}$ mode indicating a cubic-tetragonal transition at low $T$. The $c_{44}$ mode only gives a small anomaly at $T_{\mathrm{a}}$, but $c_{\mathrm{L}}=\frac{1}{2}\left(c_{11}+c_{12}+2 c_{44}\right)$ exhibits a somewhat larger softening. The $c_{11}-c_{12}$ and $c_{\mathrm{L}}$ mode we can quantitatively account for with the soft elastic mode formula [6] :

$$
\left(c_{11}-c_{12}\right)_{\Gamma}=\left(c_{11}-c_{12}\right)_{0}-\frac{g_{\Gamma}^{2} N \chi_{\mathrm{s}}}{1-g^{\prime} \chi_{\mathrm{s}}}
$$

where $g_{\Gamma}$ is the magnetoelastic coupling constant in the strain Hamiltonian

$$
\mathscr{H}_{\mathrm{str}}=-\Sigma g_{\Gamma} \varepsilon_{\Gamma} O_{\Gamma}(i)
$$

Table I. - Magnetic dipolar and quadrupolar ordering temperatures, background elastic constants, magnetoelastic and magnetic quadrupolar exchange constants in $\mathrm{TmCd}$ and $\mathrm{TmZn}$.

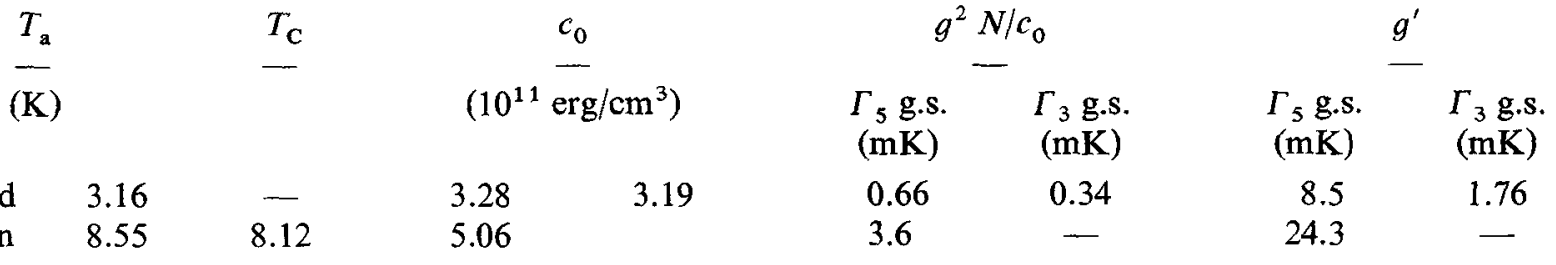



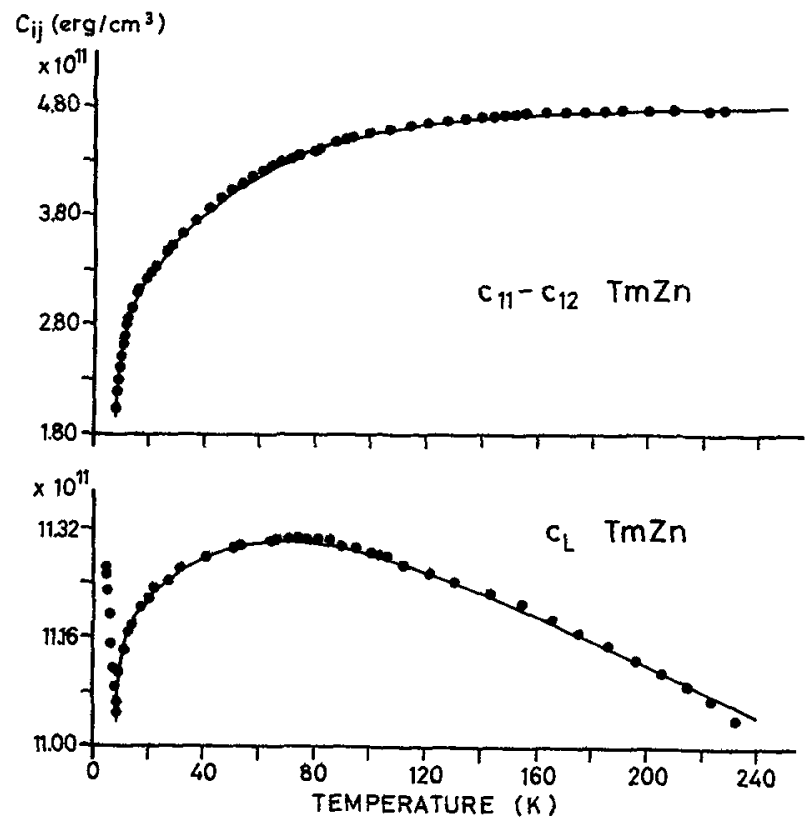

Fig. 1. - Temperature dependence of elastic constants $c_{11}-c_{12}$ and $c_{\mathrm{L}}$ for $\operatorname{TmZn}$. The solid lines are theoretical fits using eq. (1) and the parameters listed in table $I$.

and $g^{\prime}$ the quadrupolar interaction constant

$$
g^{\prime}=\Sigma^{\prime} G_{i j}
$$

in the quadrupole Hamiltonian

$$
\mathscr{H}_{\mathrm{a}}=-\Sigma G_{i j} O_{T}(i) O_{T}(j)
$$

and $\chi_{s}$ is the one ion strain susceptibility. Formula (1) was particularly successful in interpreting elastic softening for cooperative Jahn Teller phase transitions [6]. Knowing $\chi_{\mathrm{s}}$ from the CEF level system one can determine the important parameters $g_{\Gamma}^{2}, g^{\prime}$ from a temperature fit of $c_{\Gamma}$.

This gives the values of $g_{\Gamma}^{2} N / c_{0}, g^{\prime}$ quoted in table $\mathrm{I}$. Both $c_{11}-c_{12}$ and $c_{\mathrm{L}}$ give excellent agreement with theoretical fits using the same parameters $g_{\Gamma}, g^{\prime}$. For $\operatorname{TmZn}$ inelastic neutron scattering results give a $\Gamma_{5}$ ground state for the $\mathrm{Tm}^{3+}$ ion followed by a $\Gamma_{3}$ and $\Gamma_{4}$. In the ordered phase $\Gamma_{5}$ splits into a lower singlet and a higher doublet. For $\mathrm{TmCd}$ it was assumed that a nonmagnetic $\Gamma_{3}$ is the ground state in order to account for the cubic-tetragonal structural transition and the specific heat in the $\mathrm{mK}$ region [3]. This level scheme gives one set of parameters shown in table I. For a $\Gamma_{5}$ ground state, in analogy to $\mathrm{TmZn}$, one also gets a cubic-tetragonal transition and with the nonmagnetic singlet lower than the magnetic doublet one can equally well account for the hyperfine specific heat. The second set of values for $x=-0.35, W=0.9 \mathrm{~K}$ stems from this level scheme. Since inelastic neutron scattering is not possible in $\mathrm{TmCd}$ other experiments have to decide on those two competing schemes. From the values of table I one sees that $\mathrm{TmCd}$ had to order structurally in a second order transition at $T_{\mathrm{a}}^{\prime}=2.88 \mathrm{~K}$ for a $\Gamma_{3}$ ground state and at $T_{\mathrm{a}}^{\prime}=2.90 \mathrm{~K}$ for a $\Gamma_{5}$ ground state. Likewise $T m Z n$ would order at $T_{\mathrm{a}}^{\prime}=6.6 \mathrm{~K}$ in a second order transition. However the triplet ground state gives always a first order structural transition $[7,4]$.

With magnetic fields applied in the easy [100]-direction one can shift the structural transition temperature $T_{\mathrm{a}}$ to higher temperatures. This has been observed for TmCd [3] and $T m Z n$. In TmCd $T_{\mathrm{a}}$ changes from $3.16 \mathrm{~K}$ to more than $6 \mathrm{~K}$ in a field of $3 \mathrm{~T}$ and in $\mathrm{TmZn}$ similar strong effects are observed. Isochamps of the $c_{11}-c_{12}$ elastic constant show pronounced minima at $T_{\mathrm{a}}(H)$.

\section{References}

[1] JhRig, H., Vigren, D. T., KübleR, J. and Methfessel, S., Phys. Rev. B 8 (1973) 4525.

Assmus, W., Takke, R., Sommer, R., LÜthi, B., J. Phys. C 11 (1978) L-575.

[2] Ihrig, H. and LohmanN, W., J. Phys. F 7 (1977) 1957.

[3] Lüthi, B., Mullen, M. E., Andres, K., BuCher, E. and Maita, J. P., Phys. Rev. B 8 (1973) 2639.
[4] Morin, P., Rouchy, J. and Schmitt, D., Phys. Rev. B 17 (1978) 3684.

[5] Morin, P., Rouchy, J. and De Lacheisserie, E., Phys. Rev. $B 16$ (1977) 3182.

[6] Lüthi, B., AIP Conf. Proc. 34 (1976) 7.

[7] Kino, Y., LüThI, B. and Mullen, M. E., J. Phys. Soc. Japan 33 (1977) 687. 